\title{
Pre-service Science Teachers' Views of the Nature of STEM
}

\author{
Chatree Faikhamta* \\ Department of Education, Faculty of Education, Kasetsart University, Bangkok, Thailand \\ *Corresponding Author: chatreechem@yahoo.com
}

\section{ABSTRACT}

Science, Technology, Engineering, and Mathematics (STEM) education plays an important role in teaching and learning for the $21^{\text {st }}$ century. Science teacher education is making great efforts to prepare STEM teachers for modern classroom practice and enable them to adapt their STEM knowledge and practices to the needs of students' contexts. However, before developing STEM teaching practices, it is important for pre-service teachers to understand the "nature of STEM" (NOSTEM). This study explored pre-service teachers' views of the NOSTEM from both individual and integrative perspectives. The sample consisted of 428 Thai pre-service science teachers who were enrolled in science teacher-education programs. A NOSTEM questionnaire comprising Likert-type items and open-ended questions was used as a research tool. The findings indicated that pre-service teachers had inadequate understandings of NOSTEM definitions, epistemological perspectives, and the impact of culture and society on each STEM discipline. Each STEM discipline has its own characteristics, but the disciplines are similar in terms of their usefulness, processes, and required knowledge. In terms of the integration of STEM, technology uses the application of science, mathematical knowledge, and engineering processes to create tools and utensils. This paper discusses the implications of this study for science teacher-education programs and developing STEM teachers.

KEY WORDS: STEM education; nature of STEM; NOSTEM; science teacher education

\section{INTRODUCTION}

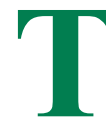

To learn any discipline, it is necessary for students to understanding its nature (McComas et al., 1998), including the impact of their epistemological beliefs and why they are learning what they learn (Peters-Burton, 2014). Empirical studies (Bell, 2008; Lederman, 1992) have shown that a better understanding of the nature of Science, Technology, Engineering, and Mathematics (NOSTEM) can function as a powerful means to develop various aspects of science students' education, helping students to better understand scientific content and maintain a positive attitude toward science and scientific attitudes. It can also help to address the current issues in the scientific community, improve students' achievements, and increase moral and ethical awareness (McComas et al., 1998).

Nowadays, it is not enough to teach a single subject. The integration of many subjects, including STEM subjects, in education (STEM education), should be prioritized as a major driving force for leading nations forward, according to the National Research Council (NRC) (2011). The integration of all four STEM disciplines, in both the classroom and real life, is the primary current trend in education that works to make learning more meaningful for students. As a result, students can better realize the value of their studies and apply their knowledge in everyday life, both of which can lead to broader job opportunities in the future and in turn boost national economies (Honey et al., 2014).

Teachers' understanding the NOSTEM is one of the key goals in STEM education. Even though NOSTEM is a new term, the importance of understanding the NOSTEM and integration (Akerson et al., 2018; Peters-Burton, 2014) can be justified by considering science education standards in many countries (Lederman 1992; McComas and Olson 1998). The Next Generation Science Standards (NGSS Lead States, 2013) assert that students should not be limited to an understanding of the nature of science (NOS), but should also understand the nature of technology (NOT), the nature of engineering (NOE), and the nature of mathematics (NOM). Kelley and Knowles (2016) stated:

Upon review of these practices across science, engineering, technology, and mathematics, the nature of these disciplines, as well as the context in which the practices occur, provides the learner with authentic examples that could help to illustrate crosscutting STEM connections. (p. 7).

Understanding the NOSTEM is one of the key elements of STEM literacy (Duschl and Bybee, 2014). Understanding the nature of an individual discipline is insufficient (NAE and NRC, 2014); rather, students and teachers should understand the interconnectedness between or among disciplines. PetersBurton (2014), in explaining the NOSTEM, asserted that each of the fields - the NOS, NOT, NOE, and NOM-has distinct definitions and key characteristics, but the nature of each subject overlaps with that of other subjects. She further argued that the NOE and NOT and the NOS and NOM are two sides of the same coin: one side (the NOE and NOT) tends to be about shaping the world, while another side (the NOS and NOM) tends to be about discovering the secrets of an already-established natural world. According to NGSS 
Appendix A (NGSS Lead States, 2013), integrating technology and engineering into science standards is not new since the NOT and the human-built environment were included in Science for All American (American Association for the Advancement of Science, 1993). The NOSTEM is embedded in both science and engineering practices and their crosscutting concepts; for example, "now engineering and technology are in the same level of science. When the students engaging science and engineering practices, that means they will understand the NOS and engineering; how it works and crosscutting concept" (NRC, 2011, p. 1-4).

An understanding of the NOSTEM can function as a powerful means to develop various aspects of STEM education, enabling students to better understand science and engineering practices and maintain a positive attitude toward STEM careers (Akerson et al., 2018; Bybee, 2011; NGSS Lead States, 2013; NRC, 2011); for example, if students understand that engineering is a design process resulting in products that meet human needs, and usually begins by identifying problems or needs, this understanding will lead students to approach engineering design processes properly and their learning will constitute STEM literacy.

Teachers play an important role in helping students to understand the NOSTEM and providing them with opportunities to learn it. Since teachers views on the nature of subjects underpin their teaching practices (e.g., Appleton and Asoko, 1996; Veal, 2004), they should develop informed opinions of the NOSTEM; for example, teachers' views of the NOS can be viewed as a conceptual map for developing and using specific teaching and learning activities and they can also be perceived as a referent that organizes teachers' knowledge (Zembal-Sual et al., 1999). Abd-El-Khalick and Lederman (2000) argued that conceptions of the NOS play a vital role in developing pedagogical content knowledge (PCK) for science teaching. They also argued that PCK includes an understanding of how to organize the theories of science along with their modes of inquiry.

Previous studies have claimed that STEM teachers have inadequate conceptions of the NOSTEM and hold naïve views of the NOS (Akerson and Donnelly, 2008), the NOT (Barak, 2012; Kruse et al., 2017), the NOE (Barak, 2012; Kelley and Knowles, 2016), and the NOM (Zollman and Mason, 1992). They seem to believe that science is the application of technology (Yalvac et al., 2007); scientific knowledge is objective and absolute (Akerson and Donnelly, 2008); scientific methods are the only way to gain knowledge (Lederman, 1992; Yalvac et al., 2007); science is a step-bystep process; technology can solve any problem (Kruse et al., 2017); technology only consists of artefacts (Kelley and Knowles, 2016); engineering design is a single, step-by-step, linear process (Kruse et al., 2017); and mathematics is a collection of rules, formulae, and procedures (Zollman and Mason, 1992). Even though in past decades, a great deal of research has examined teachers' understandings of the nature of individual STEM disciplines, very few studies have focused on the NOSTEM as a single, integrated discipline.

In this research, we assumed that, without understanding the nature of each STEM discipline and the integration of these disciplines, it is difficult for teachers to transform their understandings of the NOSTEM and provide students with opportunities to engage effectively in STEM activities. Increasing teachers' understandings of the connections between the STEM disciplines can improve their PCK (Roehrig et al., 2012); hence, we investigated pre-service teachers' understandings of the integration of STEM disciplines. An understanding of teachers' views of the NOSTEM is useful for developing STEM teacher-education programs since it can be used for setting goals, designing instructional strategies, and aligning assessment methods. It can also guide efforts to help STEM teachers increase their understandings of the NOSTEM.

\section{LITERATURE REVIEW}

In this study, we sought a framework that would be useful for investigating whether pre-service science teachers understood the NOSTEM, and the NOSTEM framework proved suitable for eliciting and evaluating their understandings of the NOSTEM. Understanding teachers' views of the NOSTEM enabled us to predict the implementation of STEM activities in real classrooms; for example, teachers who do not understand science and engineering may fail to provide students with opportunities to engage in discussions in classrooms.

As with all scientific knowledge, definitions of the NOSTEM are both tentative and dynamic. The phrase "nature of STEM" (NOSTEM) was proposed by Peters-Burton (2014). In her editorial article in "School Science and Mathematics Journal," she posed the question: "Is there a "nature of STEM"?" arguing that each field (the NOS, NOT, NOE, and NOM) has distinct definitions and key characteristics, but that overlaps exist between these disciplines. She proposed that the NOSTEM be viewed in terms of integration. According to this view, the nature of STEM is not just the sum of the NOS, NOT, NOE, and NOM; rather, it is a way of knowing that "has more depth and dimensions than we have previously offered K-12 students in each individual content area" (Peters-Burton, 2014, p. 99).

Since there is no single definition of the NOSTEM, the framework for this study was derived from the NOS conceptual framework. There have been many debates among science philosophers, science historians, and science sociologists about the specific and precise definition of the NOS, but Lederman's definition is the most widely recognized. He focused on the knowledge and sociological factors underpinning science, including creativity, imagination, subjectivity, an empirical foundation, and the importance of social and cultural values in the production of scientific knowledge, concluding that the NOS refers to the epistemology and sociology of science, science as a way of knowing, or the values and beliefs inherent in scientific knowledge and its development (Lederman, 1992). McComas et al. (1998), however, argued that the: 
NOS is the combination of various social studies of science, including the history, sociology, and philosophy of science, and research from the cognitive sciences to form a rich description of what science is, how it works, how scientists operate as a social group, and how society itself both directs and reacts to scientific endeavors (p. 4).

According to McComas et al. (1998), the NOSTEM can also be perceived as the epistemology, sociology, and values of STEM, guiding specific questions as follows:

- What is STEM?

- What is STEM integration?

- How does STEM work?

- How does society both direct and react to STEM endeavors?

Based on these arguments, the NOSTEM relates to subjectspecific content that has its own concepts, technical terms, and topics. The NOSTEM is a description of STEM characteristics that emerged from a combination of the epistemology and sociology of STEM. The descriptions of STEM characteristics can refer to what STEM is, how it works, and/or how it interacts with culture and society. In this study, we did not assume that this definition of the NOSTEM was absolute but instead used it as a lens through which to examine people's views of STEM.

The definition of STEM is often a subject of great debate, defined from various perspectives. STEM is an acronym referring to the study of, or professional practice in, the broad areas of STEM (Hernadez et al., 2014) and has been used in diverse academic fields. The word STEM was initially applied to undergraduate courses, but its meaning has expanded, now implying more than simply a combination of four educational disciplines and being used across all grade levels, from preschool to post-doctorate. STEM education has been defined as a comprehensive and interdisciplinary teaching and learning approach to those four disciplines (Gonzales and Kuenzi, 2012) in both formal (classroom) and informal (extracurricular) settings. However, Bybee (2013) argued that STEM can be defined from multiple perspectives. He proposed the possibility of STEM definitions being used in single discipline, interdisciplinary, and transdisciplinary terms. However, PetersBurton (2014) argued that STEM should involve the integration of STEM subjects, not be a single discipline. Understanding the nature of disciplines and their integration is important for science and engineering practice. According to the Committee on Integrated STEM Education:

Connecting ideas across disciplines is challenging when students have little or no understanding of the relevant ideas in the individual disciplines. Furthermore, students do not always or naturally use their disciplinary knowledge in integrated contexts. Students will thus need support to elicit the relevant scientific or mathematical ideas in an engineering or technological design context, to connect those ideas productively, and to reorganize their own ideas in ways that come to reflect normative, scientific ideas, and practices (NAE and NRC, 2014, p. 5).
To describe the complexity among, and interactions between, STEM disciplines is challenging. The integrative features of STEM disciplines have been described by the lead state partners in the recent NGSS (NGSS Lead States, 2013), which provide a clear pathway for connecting the NOS, NOT, NOE, and NOM with science and engineering practices and crosscutting concepts. Eight science and engineering practices (NGSS Lead States, 2013) have common features and interact across disciplines. In their investigations, in the case of scientists, and engineering processes, in the case of engineers, both scientists and engineers have developed and used models; planned and carried out investigations; analyzed and interpreted data; employed mathematics and computational thinking; engaged in argument on the basis of evidence; and obtained, evaluated, and communicated information. Engineering and science are similar in that both involve creative processes, and neither uses only one method. In addition, STEM are interdependent. In both scientific investigations and engineering processes, technology and mathematics are used as a tool and process to extend the range of investigation and problem-solving. Yalvac et al. (2007) discussed the influence of science and technology on society, and the influence of society on science and technology, as well as the potential impact of social circumstances. Similarly, Garibay (2015) pointed out the critical and social aspects of STEM education that can help students to understand the social impact of STEM practices.

In terms of crosscutting concepts (NGSS Lead States, 2013), seven concepts have been discussed: Patterns; cause and effect; scale, proportion, and quantity; systems and system models; energy and matter; structure and function; and stability and change. These crosscutting concepts reflect the commonality and integrative features of STEM disciplines; for example, scientists seek explanations for observed patterns and for the similarity and differences between them, while engineers also frequently look for and analyze patterns. Scientists and engineers use mathematical representations in terms of scale, proportion, and quantity to better understand natural phenomena and increase the precision and validity of their investigations and solutions.

Some studies have focused on the integrative features of STEM. Interestingly, the US Minnesota state standards explicitly addressed the intersection of the STEM disciplines with reference to the nature of the science and engineering strands (Roehrig et al., 2012). However, the NOS and NOE are intended to be embedded in teaching and learning activities (Roehrig et al., 2012), meaning that the practice of science should include an understanding of the NOS and scientific inquiry and investigation, while the practice of engineering should include an understanding of the NOE and engineering design. In relation to the interactions between science, technology, engineering, mathematics, and society, the standards were intended to help students understand STEM integration in terms of the mutual influences of science, engineering, and society, and the role of mathematics and technology in science and engineering. 


\section{METHODOLOGY}

\section{Context of the Study}

The sample for this study comprised 428 Thai pre-service science teachers enrolled in 5-year teacher-education programs across the country. All science teachers read an informed consent and voluntarily agreed to participate before completing the questionnaire. These teachers were being prepared for employment as primary or middle school science teachers who could facilitate STEM activities in their classrooms. The programs required the pre-service teachers to study science content drawn from the faculty of science and pedagogy and pedagogical content knowledge drawn from the faculty of education. The selection of the study sample was guided by practical considerations, such as gaining access to relevant data within the constraints of time, funding, and logistics; hence, purposive and convenience sampling was used (Saumure, 2008). The demographics of the sample are shown in Table 1.

Most of the pre-service teachers were female (79.21\%). All these pre-service teachers were drawn from years 1 to 5 of various subjects (chemistry education, biology education, physics education, earth and space science education, and general science education). It was clear that pre-service teachers studying general science education predominated.

\section{The NOSTEM Questionnaire}

This study developed and administered a NOSTEM questionnaire, adapted from the "Students Understanding Science and Scientific Inquiry" (SUSSI) instrument (Liang et al., 2008). The development and assessment of students' and teachers' understandings of the nature of the STEM disciplines have been a concern in the sciences for more than 50 years, up to the late 1990s; for example, the NOS assessment of teachers and students was standardized as a forced-choice, paper-andpencil test, comprising forced-choice, multiple-choice items

\begin{tabular}{lcc}
\hline $\begin{array}{l}\text { Table 1: Demographic data of the pre-service science } \\
\text { teachers }\end{array}$ & $\begin{array}{c}\text { Number of } \\
\text { sample }\end{array}$ & $\begin{array}{c}\text { Percentage of } \\
\text { sample }\end{array}$ \\
\hline Demographic data & & \\
& 339 & 79.21 \\
\hline Gender & 89 & 20.79 \\
Female & & \\
Male & 19 & 4.44 \\
Year & 106 & 24.77 \\
Year 1 & 104 & 23.30 \\
Year 2 & 118 & 27.57 \\
Year 3 & 89 & 18.93 \\
Year 4 & & \\
Year 5 & 5 & 1.17 \\
Major & 11 & 2.57 \\
Chemistry education & 36 & 8.41 \\
Biology education & 7 & 1.64 \\
Physics education & 346 & 80.84 \\
Earth and space science education & 23 & 5.37 \\
General science education & & \\
Others & &
\end{tabular}

requiring true/false, agree/disagree, and Likert-type answers. However, Lederman et al. (2002) argued that a standardized paper-and-pencil test would ultimately impose the developers' views on the respondents, rather than revealing the respondents' views, which could result in researcher bias (Lederman et al., 2002). Moreover, the validity of the instrument was doubtful. Now, the leading assessment tool used to assess students' and teachers' views of the NOS is the "Views of Nature of Science" (VNOS) Questionnaire developed by Lederman et al. (2002), which has high validity and reliability.

However, Liang et al. (2008) held the view that using VNOS instruments posed some challenges for respondents with limited knowledge of the NOS and limited writing skills, who might not be able to fully express their ideas, thus limiting the potential value of using VNOS instruments alone as either formative classroom assessment forms or accurate research tools. Moreover, VNOS instruments are not appropriate for assessing many participants' views of the NOS. SUSSI is another assessment tool used to assess students' understanding of science, which was developed by Liang et al. (2008). It is less time-consuming than VNOS and can be used as a summative assessment tool to measure students' levels of understandings of NOS-related issues.

The NOSTEM questionnaire, to assess participants' understandings of the NOSTEM, consisted of 16 items. All the items were developed based on the literature review. Table 2 presents the integrative features of STEM, with a focus on the interconnectedness and influence of STEM on culture and society. For interconnectedness, the interdependence between any two disciplines, such as $\mathrm{S}-\mathrm{T}, \mathrm{S}-\mathrm{M}, \mathrm{S}-\mathrm{E}$, or $\mathrm{T}-\mathrm{E}$, and the interconnectedness of various STEM disciplines were examined. Thereafter, STEM's influence on culture and society, and vice versa, was examined. Like SUSSI, the NOSTEM questionnaire consisted of five-point rating scales ( 1 = "absolutely not true," 2 = "slightly true," 3 = "partly true," 4 = "very true," 5 = "absolutely true"). The questionnaire's scales were developed based on the aforementioned core dimensions: The interconnectedness and influence of STEM.

Confirmatory factor analysis was conducted to ensure the validity of the NOSTEM questionnaire. Confirmative analysis of components using LISREL has shown that normal theory weighted least square Chi-square $=3737.86$ $(p=0.0)$, degrees of freedom $=1443$, additionally, normed fit index $=0.95$, comparative fit index $=0.97$, root mean square error of approximation $=0.065$, root mean square residual $(\mathrm{RMR})=0.055$, and standardized $\mathrm{RMR}=0.096$. All the fit statistics index has fulfilled the requirement condition (Hu and Bentler, 1995). This indicates that the NOSTEM questionnaire is acceptable in measuring all the constructs of the nature of STEM.

\section{Data Collection and Analysis}

The NOSTEM questionnaire was distributed to pre-service science teachers at eight universities across Thailand. First, an invitation was sent to the chairperson of each teacher education 


\begin{tabular}{|c|c|c|}
\hline NOSTEM perspectives & Domain & Dimensions \\
\hline \multirow[t]{12}{*}{ Individual } & Nature of science & 1. What is science? \\
\hline & & 2. How do scientists work? \\
\hline & & 3. How do culture and society influence science and vice versa? \\
\hline & Nature of technology & 4. What is technology? \\
\hline & & 5. How do technologists work? \\
\hline & & 6. How do culture and society influence technology and vice versa \\
\hline & Nature of engineering & 7. What is engineering? \\
\hline & & 8. How do engineers work? \\
\hline & & 9. How do culture and society influence engineering and vice versa? \\
\hline & Nature of mathematics & 10. What is mathematics? \\
\hline & & 11. How do mathematicians work? \\
\hline & & 12. How do culture and society influence mathematics and vice versa? \\
\hline \multirow[t]{9}{*}{ Integrated } & Interconnectedness & 13. What is the interdependence between: \\
\hline & & a. Science and technology \\
\hline & & b. Science and mathematics \\
\hline & & c. Science and engineering \\
\hline & & d. Technology and engineering \\
\hline & & e. Technology and mathematics \\
\hline & & f. Engineering and mathematics \\
\hline & & 14. Integration of STEM subjects \\
\hline & Influence of culture and society & 15. How do culture and society influence integrated STEM and vice versa? \\
\hline
\end{tabular}

STEM: Science, Technology, Engineering, and Mathematics, NOSTEM: Nature of Science, Technology, Engineering, and Mathematics

program and he or she asked their pre-service teachers to complete the questionnaire. The data were analyzed to compare the means and the standard deviations for each scale on the questionnaire. For the qualitative data elicited by the single open-ended question, the pre-service teachers' responses were analyzed using the constant comparative method (CCM) (Lincoln and Guba, 1985). The CCM is a process that leads to successive data reduction by comparing incidents applicable to each category; integrating categories and their properties; delimiting the theory; and categories and their properties are reduced and refined.

\section{FINDINGS}

Pre-service teachers' responses to the Likert-type items and open-ended questions revealed views of the NOSTEM that related to five aspects: The NOS, the NOT, the NOE, the NOM, and integrated STEM, respectively. For each aspect, pre-service teachers' views were first analyzed as represented by the Likert-type items, then the patterns of the participants' responses to the open-ended question were identified.

\section{NOS}

As shown in Table 3, the Likert-type items elicited pre-service teachers' views on what science is, how science and scientists work, and the interrelationship between science, technology, and society.

It was found that pre-service science teachers held intermediate views regarding what science is (items 1-3). They believed that science is primarily concerned with understanding how the natural world works; however, they tended to view science as a search for the truth rather than a means of constructing explanations for natural phenomena. They also failed to understand that science cannot answer all questions. Similarly, in their responses to the open-ended questions, many of the participants exhibited intermediate views on what science is. The top five answers ranked by pre-service teachers, regarding what science is, are shown below:

- "Science is an investigation of things around us."

- "Science is the knowledge that explains the natural phenomena around us."

- "Science is the things around us that can be proved by evidence."

- "Science is a search for the truth."

- "Science is experimentation and logical thinking."

In respect of how scientists work (items 4-8), pre-service teachers held the informed view that, once scientists obtain a result from an experiment, there are many possible answers. Interestingly, they agreed that the scientific method is the only way to investigate scientific knowledge and that the scientific method is a step-by-step process. They held intermediate views in respect of the influence of culture on science. They agreed that scientific research is not influenced by society and culture, but contradictorily agreed that cultural values and expectations determine what science is conducted and accepted.

\section{NOT}

As shown in Table 4, the Likert-type items elicited pre-service teachers' views on definitions of technology, the design of technology, and interrelationship between science, technology, and society. 


\section{Table 3: Pre-service science teachers' views of the NOS}

\begin{tabular}{|c|c|c|c|c|}
\hline Statement & & Mean & SD & Interpretation \\
\hline 1. NOS1 & Science is primarily a search for truth. & 3.36 & 0.67 & Strongly agree \\
\hline 2. NOS2 & Science can solve all kinds of problems or questions. & 2.66 & 0.75 & Agree \\
\hline 3. NOS3 & Science is primarily concerned with understanding how the natural world works. & 3.30 & 0.67 & Strongly agree \\
\hline 4. NOS4 & Scientists use models to develop explanations for natural phenomena. & 3.29 & 0.67 & Strongly agree \\
\hline 5. NOS5 & Scientists always use the scientific method to design their experiments. & 3.08 & 0.78 & Agree \\
\hline 6. NOS6 & Scientists follow the same step-by-step scientific method. & 2.42 & 0.74 & Agree \\
\hline 7. NOS7 & Once scientists obtain a result from an experiment, there is only one answer. & 2.29 & 0.84 & Disagree \\
\hline 8. NOS8 & Scientists' observations of the same event will be the same, because scientists think in a similar way. & 2.18 & 0.83 & Disagree \\
\hline 9. NOS9 & Scientific research is not influenced by society and culture. & 2.39 & 0.83 & Agree \\
\hline 10. NOS10 & Cultural values and expectations determine what science is conducted and accepted. & 2.70 & 0.72 & Agree \\
\hline
\end{tabular}

\section{Table 4: Pre-service science teachers' views of the NOT}

\begin{tabular}{|c|c|c|c|c|}
\hline Statement & & Mean & SD & Interpretation \\
\hline 1. NOT1 & Technology is an applied science. & 3.14 & 0.69 & Agree \\
\hline 2. NOT2 & Technology is the integration of knowledge of science, mathematics, and other disciplines to create utensils. & 3.25 & 0.71 & Agree \\
\hline 3. NOT3 & Technology is ideas and techniques for designing and manufacturing things for the progress of society. & 3.20 & 0.71 & Agree \\
\hline 4. NOT4 & An example of technology is a bird trap. & 2.97 & 0.71 & Agree \\
\hline 5. NOT5 & Technology has continually been developed in response to the problems and needs of humans. & 3.39 & 0.72 & Strongly agree \\
\hline 6. NOT6 & A technological system comprises three components (input, process, and output) that work interdependently. & 3.13 & 0.68 & Agree \\
\hline 7. NOT7 & $\begin{array}{l}\text { The decision to use new technology depends on its cost, efficiency, usefulness to society, and effect on } \\
\text { employment. }\end{array}$ & 3.18 & 0.67 & Agree \\
\hline 8. NOT8 & The decision to use new technology does not necessarily depend on how well the new technology will work. & 2.78 & 0.82 & Agree \\
\hline 9. NOT9 & Technologists can invent anything without considering society and culture. & 2.92 & 0.77 & Agree \\
\hline 10. NOT10 & Citizens are in charge of technological developments. & 3.31 & 0.71 & Strongly agree \\
\hline
\end{tabular}

Pre-service science teachers were found to believe that technology is an applied science and only consists of artefacts. Even though they agreed that technology is the integration of knowledge of science, mathematics, and other disciplines to create utensils, their responses to the open-ended questions showed that they viewed technology as only consisting of artefacts:

- "Technology is tools such as mobile phones."

- " "Technology is utensils for serving our needs."

- "Technology is modern inventions created by human beings."

- "Technology is a new thing."

- "Technology is an applied science."

Very few pre-service teachers thought of technology as a process for doing something or solving practical problems; rather, they thought that it related to inventing, designing, and testing things. They held intermediate views in that they strongly believed technology has continually developed in response to the problems and needs of humans; however, they also believed that a technological system comprises three components (input, process, and output) that work interdependently.

Regarding the impact of societal and cultural influences on technology, even though pre-service teachers agreed that citizens are in charge of technological developments, they nevertheless agreed that technologists can invent anything without considering society and culture.

\section{NOE}

As shown in Table 5, pre-service teachers gave their views on definitions of engineering, engineering processes, and the impact of cultural and societal influences.

It was found that pre-service science teachers held intermediate views on all these aspects. They viewed engineering as a design process, which starts with problems, needs, or desires, and questions. Similarly, in their open-ended responses, many of the pre-service teachers claimed that engineering is a process:

"Engineering is designing things such as houses."

"Engineering is constructing things"

However, the use of the word things might indicate that the teachers believed engineering must create a product, a thing, rather than develop a process. Some of the pre-service teachers held the view that engineering is designing things using knowledge of science and mathematics, but some of them believed that engineering constructs artefacts and utensils, such as houses and robots.

In terms of engineering processes, they had a sound understanding that engineering designs aim to meet human needs and that they begin with the identification of a problem 
and end with a solution that takes into account identified constraints and meets specifications for desired performance; however, they failed to understand that design is an iterative process. They held the informed view that political considerations can place constraints on the design process.

\section{NOM}

As in shown in Table 6, pre-service teachers gave their views on definitions of mathematics, mathematical processes, and the cultural and societal influences on mathematical processes.

According to the Likert-scale items, pre-service teachers tended to believe that mathematics is a collection of facts, skills, and rules applied in different situations. This deduction was supported by their responses to the open-ended questions. The pre-service teachers thought that:

- "Mathematics is the calculation of numbers."

- "Mathematics is a fact that is unchangeable."

- "Mathematics is calculating to seek relationships."

- "Mathematics is numbers and equations."

Very few pre-service teachers thought of mathematics as a cycle of inquiry that begins with the representation of quantities as abstract symbols, accounting for all possibilities through the manipulation of rules, and validating the quality of solutions and models.

Pre-service teachers held intermediate views of mathematical processes. They agreed that mathematics is a process, rather than a product and that mathematicians construct viable arguments and critique the reasoning of others; however, they also thought that mathematics does not rely on logic and creativity. Interestingly, in terms of cultural influences, they thought that mathematicians often create patterns without considering society and cultural influences.

\section{Nature of Integrated STEM}

As in shown in Table 7, the Likert-type items elicited preservice teachers' views on integrated STEM, as denoted by the interdependence between any two disciplines ( $\mathrm{S}-\mathrm{T}, \mathrm{S}-\mathrm{M}, \mathrm{S}-\mathrm{E}$, or $\mathrm{T}-\mathrm{E}$ ), and the interconnectedness of various combinations of STEM disciplines.

It was found that pre-service science teachers held informed views regarding some aspects; for example, they agreed that mathematics is a key tool for understanding engineering and that new scientific knowledge can contribute to new technology. However, they were somewhat confused in believing that technology and engineering are the same. Preservice teachers did not perceive much interconnectedness between disciplines, believing that STEM have their own characteristics, which do not overlap.

The open-ended questions asked pre-service teachers to give their views on the similarities, differences, or interconnectedness between STEM disciplines. Most

\section{Table 5: Pre-service science teachers' views of the NOE}

\begin{tabular}{|c|c|c|c|c|}
\hline Statement & & Mean & SD & Interpretation \\
\hline 1. NOE1 & Engineers begin with questions. & 3.07 & 0.74 & Agree \\
\hline 2. NOE2 & Engineers begin with a problem, need, or desire. & 3.25 & 0.70 & Agree \\
\hline 3. NOE3 & $\begin{array}{l}\text { Engineers analyze and interpret data collected from the testing of designs and investigations to locate } \\
\text { optimal design solutions. }\end{array}$ & 3.13 & 0.66 & Agree \\
\hline 4. NOE4 & Engineers fix things. & 2.45 & 0.81 & Disagree \\
\hline 5. NOE5 & All design processes have constraints. & 2.82 & 0.78 & Agree \\
\hline 6. NOE6 & Engineers use modeling to understand how a product or component may function when in use. & 3.17 & 0.68 & Agree \\
\hline 7. NOE7 & Engineers design with the goal of meeting human needs and wants. & 3.20 & 0.64 & Agree \\
\hline 8. NOE8 & Engineers use models and simulations to analyze existing solutions. & 3.13 & 0.60 & Agree \\
\hline 9. NOE9 & Design is a step-by-step process. & 2.55 & 0.77 & Agree \\
\hline 10. NOE10 & Political consideration can be one of the constraints on the design process. & 2.76 & 0.72 & Agree \\
\hline
\end{tabular}

\section{Table 6: Pre-service science teachers' views on the NOM}

\begin{tabular}{|c|c|c|c|c|}
\hline Statement & & Mean & SD & Interpretation \\
\hline 1. NOM1 & Mathematics is the science of patterns and relationships. & 3.07 & 0.65 & Agree \\
\hline 2. NOM2 & Mathematics is a static body of integrated pre-existing knowledge awaiting discovery. & 2.71 & 0.82 & Agree \\
\hline 3. NOM3 & Mathematics is a collection of facts, skills, and rules applied in different situations. & 3.01 & 0.64 & Agree \\
\hline 4. NOM4 & Mathematics is a process rather than a product. & 2.91 & 0.71 & Agree \\
\hline 5. NOM5 & Mathematics does not rely on logic and creativity. & 2.54 & 0.82 & Agree \\
\hline 6. NOM6 & Mathematicians construct viable arguments and critique the reasoning of others. & 2.63 & 0.74 & Agree \\
\hline 7. NOM7 & Mathematical thinking often beings with a process of abstraction. & 2.87 & 0.66 & Agree \\
\hline 8. NOM8 & Mathematics is used to express ideas or to solve problems. & 3.01 & 0.62 & Agree \\
\hline 9. NOM9 & Mathematicians often create patterns without considering society and cultural influences. & 2.64 & 0.79 & Agree \\
\hline 10. NOM10 & Mathematicians work separately from others. & 2.33 & 0.84 & Disagree \\
\hline
\end{tabular}




\begin{tabular}{|c|c|c|c|c|}
\hline Statement & & Mean & SD & Interpretation \\
\hline 1. ST1 & Technology draws on science and contributes to it. & 3.25 & 0.66 & Agree \\
\hline 2. ST2 & New scientific knowledge can contribute to new technology. & 3.36 & 0.65 & Strongly agree \\
\hline 3. SE1 & Engineering design is often separated from necessary scientific processes. & 2.43 & 0.95 & Disagree \\
\hline 4. SE2 & Engineering affects the social system and culture more directly than scientific research. & 2.65 & 0.73 & Agree \\
\hline 5. SM1 & Science and mathematics are similar in terms of ideals of honesty and openness. & 3.06 & 0.65 & Agree \\
\hline 6. SM2 & Science provides mathematics with interesting problems to investigate. & 2.89 & 0.66 & Agree \\
\hline 7. TE1 & Technology and engineering are the same. & 2.69 & 0.76 & Agree \\
\hline 8. TE2 & Engineers use design processes to develop technology. & 3.10 & 0.61 & Agree \\
\hline 9. TM1 & $\begin{array}{l}\text { The mathematics of connections and logical chains, for example, has contributed greatly to the design } \\
\text { of computer hardware. }\end{array}$ & 3.18 & 0.64 & Agree \\
\hline 10. TM2 & New technology can contribute to new mathematical knowledge. & 3.04 & 0.65 & Agree \\
\hline 11. EM1 & $\begin{array}{l}\text { Engineers use mathematics to describe and analyze data and, as noted, to develop models for evaluating } \\
\text { design solutions. }\end{array}$ & 3.16 & 0.62 & Agree \\
\hline 12. EM2 & Mathematics is a key tool for understanding engineering. & 3.09 & 0.61 & Agree \\
\hline 13. STEM1 & $\begin{array}{l}\text { Science, technology, engineering, and mathematics have their own characteristics, which do not } \\
\text { overlap. }\end{array}$ & 2.67 & 0.80 & Agree \\
\hline 14. STEM2 & $\begin{array}{l}\text { Engineers use science and mathematics in their work, and scientists and mathematicians use the } \\
\text { products of engineering-technology. }\end{array}$ & 3.05 & 0.66 & Agree \\
\hline 15. STEM3 & $\begin{array}{l}\text { The development of knowledge in technology, science, mathematics, and other disciplines contributes } \\
\text { to new technology and continual change. }\end{array}$ & 3.27 & 0.63 & Agree \\
\hline
\end{tabular}

participants saw some similarities between STEM disciplines in terms of usefulness, processes, and knowledge. Some examples of their responses are shown below:

- "They (the STEM disciplines) are similar because we can use them for making our lives better."

- "They are similar in terms of ways of thinking, such as using calculations to create and construct things."

- "They are similar because they use processes to reach the answers."

- "They are similar because they can prove what we already know."

- "They are similar because they depend on principles and theories."

- "STEM disciplines are similar in terms of using new knowledge to create and design (things). Creating something needs some relationship between science, technology, and engineering knowledge."

- Some participants thought that STEM disciplines were different but related to each other. Most of them merely differentiated between science and engineering, using statements such as;

- "STEM disciplines are different but can be integrated."

- "Each discipline is different in terms of ideas and practices, but they are all related and brought into design."

- "They are different, but when we apply them, they should be integrated."

In terms of interconnectedness, some pre-service teachers held the view that all the STEM disciplines must be integrated to invent new things that meet human needs. Some pre-service teachers viewed technology as products created by fusing scientific, mathematical, and engineering knowledge. They explained that to create things, we need a scientific process to obtain knowledge, while mathematics helps us to analyze and calculate things precisely. Some participants explained that STEM disciplines are concerned with problem-solving, using and creating models, manipulating data, and explaining phenomena. They thought that some features of science and engineering are similar in terms of developing and creating models, designing products, conducting research, and collecting and analyzing data, while technology is a tool that helps those processes to be accomplished. Examples of their responses are given below:

- "Technology is the application of science, which requires engineering and mathematics (knowledge) to create things. Mathematics can help us calculate and engineering is about designing things in response to our needs."

- "Technology is tools or devices that make things more convenient by bringing scientific and mathematical knowledge into the design process and then producing new technology."

\section{DISCUSSION, CONCLUSIONS, AND IMPLICATIONS}

This research study contributes to a broad understanding of pre-service science teachers' views on the nature of STEM. Understanding the nature of the STEM disciplines is a prerequisite for the deep literacy necessary for our students to meaningfully participate in informed dialogue and decisionmaking. However, the results of this study indicated that pre-service teachers have naive understanding, as shown by their Likert scale responses and answers to the open-ended questions. Most of these pre-service teachers viewed science, technology, and mathematics as products and engineering as a process. Their views on the NOSTEM were consistent with 
those suggested in the literature for the NOS (Akerson et al., 2000), the NOT (Kruse et al., 2017), the NOE (Kruse et al., 2017; Pleasants and Olson, 2018), and the NOM (Zollman and Mason, 1992). Pre-service teachers viewed science as relating to the things around them and knowledge that explains natural phenomena. They saw science as a search for the truth, rather than a means to construct explanations of natural phenomena (Abd-El-Khalick and BouJaoude, 1997; Akerson and Donnelly 2008). The participants seemed to believe that science is the application of technology (Yalvac et al., 2007) and viewed technology as only consisting of artefacts such as tools or utensils (Barak, 2012; Kelley and Knowles, 2016). Engineering was viewed as the design and construction of things such as houses. This might indicate that teachers believe engineering must create a product, a thing, rather than develop a process (Boesdorfer, 2017). They also thought that mathematics involves numerical calculation and collections of facts and rules (Zollman and Mason, 1992).

With regard to how STEM professionals work, pre-service teachers tended to believe that all disciplines share common characteristics and a linear, step-by-step process; for example, even though pre-service teachers understood that engineering involves many processes, they believed that engineering design is a single, step-by-step, linear process. This finding was in line with the work of Kruse et al. (2017), who pointed out the NOE myth that engineering design is a single, step-by-step, linear process and engineering is any problem-solving or design activity. In fact, engineering consists of iterative processes and it is not restricted to problem-solving endeavors but uses scientific and mathematical knowledge to inform design.

Regarding the cultural, societal, and political influences of STEM, pre-service teachers held intermediate views; for example, they believed that engineering design responds to, and meets, human needs, but technologists can invent anything without considering society and culture. Pre-service teachers understood the interdependence of technology and culture and that the decision to use new technology depends on several factors such as its cost, efficiency, usefulness to society, and effect on employment, but some of them believed that the decision to use the new technology does not necessarily depend on how well the new technology will work (Yalvac et al., 2007). This finding was inconsistent with the idea suggested by Herschbach (2009) and Kelley and Knowles (2016): That technology has various dimensions, such as influencing the cultural/social order, regardless of its users' intentions; serving human values and influencing value formation; autonomous social and economic forces that often override traditional and competing values; and the potential for leading to unexpected positive or destructive social and economic consequences.

Pre-service teachers saw some similarities between disciplines, in that STEM, have their own characteristics but are similar in terms of their usefulness, processes, and knowledge; for example, they thought that STEM disciplines are similar because they depend on principles and theories. This idea was inconsistent with the proposal of Kruse et al. (2017), who suggested that the NOT has similarities to the NOS in its definitions, value-laden aspects, limitations, ways of developing knowledge, and social influences. In fact, the nature of each discipline has its own characteristics, based on its history, sociology, philosophy, and research.

Interestingly, this research indicated that pre-service science teachers' views on STEM integration were consistent with the view that "science and math are connected by technology and/ or engineering" - one of the nine perspectives proposed by Bybee (2013). According to this perspective, STEM consist of science and mathematics connected by technological and engineering concepts (Figure 1).

Most of the participants thought that technology is a product created by combining scientific, mathematical, and engineering knowledge; that is, technology is the application of science, which uses engineering and mathematical knowledge to create things. It is tools or devices that make things more convenient by bringing scientific and mathematical knowledge into engineering design processes.

This study supports the idea that pre-service teachers should understand the common features of STEM disciplines. Kelley and Knowles (2016) suggested that to prepare STEM educators, a conceptual understanding of integrated STEM education must be a prerequisite for teaching. Pre-service teachers should understand seven crosscutting concepts (NGSS Lead States, 2013): patterns, cause and effect, scale, proportion and quantity, systems and system models, energy and matter, structure and function, and stability and change. These crosscutting concepts reflect the commonality and integrative features of STEM disciplines; for example, scientists seek explanations for observed patterns and for the similarity and diversity within them, while engineers also frequently look for and analyze patterns. Scientists and engineers use mathematical representations in terms of scale, proportion, and quantity to better understand natural phenomena and increase the precision and validity of their investigations and solutions.

This, in turn, implies that science teacher educators should focus on using the NOSTEM as a framework, as proposed by Peters-Burton (2014), to develop pre-service teachers' understandings of the nature of the STEM disciplines and their integration. This study recommends that STEM courses in teacher-education programs should initially provide pre-service teachers with opportunities to develop their understandings of the NOSTEM and help them to deliver that

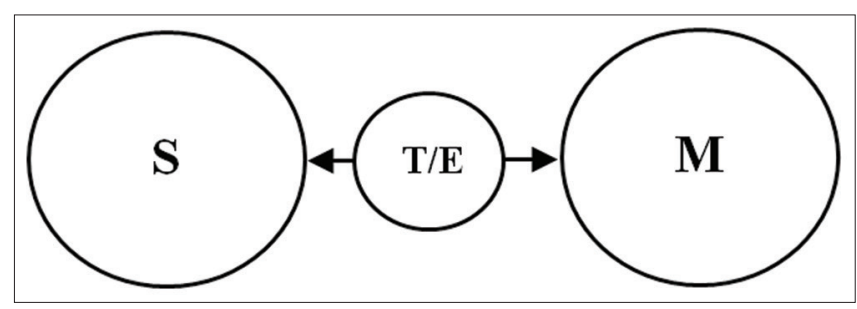

Figure 1: STEM integration perspective 
understanding to their students in classrooms. In these courses, pre-service teachers should have the chance to analyze the NOSTEM in science curricula, consider students' conceptions of the NOSTEM, develop NOSTEM PCK, assess students' understandings of the NOSTEM, and learn how to make certain features of the NOSTEM explicit to students.

Unfortunately, this study was limited since the researchers did not have opportunities to probe more deeply into preservice teachers' views of the NOSTEM. As a result, further elucidation of pre-service teachers' views would enable us to understand more about their views of the NOSTEM and the reasons behind them. This study recommends that science education research should investigate teachers' understandings of the NOSTEM more thoroughly. Most of the research on STEM education has focused on professional development programs and investigated their impact on various factors such as teachers' teaching skills (Rinke et al., 2016; Roehrig et al., 2012), their attitudes toward STEM education (Berlin and White, 2012), or their perceptions and self-efficacy (Srikoom et al., 2018). Very few researchers have investigated teachers' understandings of the key features of STEM, particularly from both individual and integrative perspectives. As asserted by Bybee (2011), there is a need for science teachers and those in teacher education programs to recognize the similarities and differences between science and technology as disciplines and subsequently the practices that characterize the disciplines (p. 6).

In addition, to extend this study, it would be useful to follow up on how the pre-service teachers integrated their understandings of the NOSTEM into their classroom practices. This kind of study would provide an in-depth understanding of whether, and how strongly, their understandings of the NOSTEM related to their STEM teaching practices (Akerson et al., 2018; Roehrig et al., 2012). This type of empirical study would significantly add to the value of the concepts of both the NOSTEM and STEM PCK (Srikoom et al., 2018) within the domain of science teacher education.

\section{REFERENCES}

Abd-El-Khalick, F., \& BouJaoude, S. (1997). An exploratory study of the knowledge base for science teaching. Journal of Research in Science Teaching, 34(7), 673-699.

Abd-El-Khalick, F., \& Lederman, N. (2000). The Influence of history of science courses on students' views of nature of science. Journal of Research in Science Teaching, 37(10), 1057-1095.

Akerson, V.L., \& Donnelly, L.A. (2008). Relationships among learner characteristics and preservice elementary teachers' views of nature of science. Journal of Elementary Science Education, 20(1), 45-58.

Akerson, V.L., Burgess, A., Gerber, A., Guo, M., Khan, T.A., \& Newman, S. (2018). Disentangling the meaning of STEM: Implications for science education and science teacher education, Journal of Science Teacher Education, 29(1), 1-8.

American Association for the Advancement of Science. (1993). Benchmarks for Science Literacy: A Project 2061 Report. Oxford: Oxford University Press.

Appleton, K., \& Asoko, H. (1996). A case study of a teacher's progress toward using a constructivist view of learning to inform teaching in elementary science. Science Education, 80, 165-180.
Barak, M. (2012). Teaching engineering and technology: Cognitive, knowledge and problem-solving taxonomies. Journal of Engineering, Design, and Technology, 11(3), 316-333.

Bell, R.L. (2008). Teaching the Nature of Science through Process Skills: Activities for Grades 3-8. Boston: Allyn \& Bacon/Longman.

Berlin, D.F., \& White, A.L. (2012). A longitudinal look at attitudes and perceptions related to the integration of mathematics, science, and technology education. School Science and Mathematics, 112(1), 20-30.

Boesdorfer, S.B. (2017). Is engineering inspiring change in secondary chemistry teachers' practices? Journal of Science Teacher Education, 28(7), 609-630.

Bybee, R. (2013). The Case for STEM Education: Challenges and Opportunities. Virginia: National Science Teachers Association Press.

Bybee, R.W. (2011). Scientific and Engineering Practices in K-12 Classrooms Understanding: A Framework for K-12 Science Education. Available from: https://static.nsta.org/ngss/resources/201112 Framework-Bybee. pdf.

Duschl, R.A., \& Bybee, R.W.(2014). Planning and carrying out investigations: An entry to learning and to teacher professional development around NGSS science and engineering practices. International Journal of STEM Education, 1(12), 1-9.

Garibay, J.C. (2015). STEM students' social agency and views on working for social change: Are STEM disciplines developing socially and civically responsible students? Journal of Research in Science Teaching, 52(5), 610-632.

Gonzalez, H.B., \& Kuenzi, J. (2012). Congressional Research Service Science, Technology, Engineering, and Mathematics (STEM) Education: A Primer. Washington, DC: Congressional Research Service.

Hernandez, P.R., Bodin, R., Elliott, J.W., Ibrahim, B. Rambo-Hernandez, K.E., Chen, T.W., \& de Miranda, M.A. (2014). Connecting the STEM dots: Measuring the effect of an integrated engineering design intervention. International Journal of Technology and Design Education, 24(1), 107-120.

Herschbach, D. (2009). Technology Education: Foundations and Perspectives. New York: American Technical Publishers, Inc.

Honey, M., Pearson, G., \& Schweingruber, H. (2014). STEM Integration in K-12 Education: Status, Prospects, and an Agenda for Research Engineering. Washington, DC: The National Academies Press.

Hu, L.T., \& Bentler, P.M. (1995). Evaluating model fit. In: Hoyle, R., (Ed.), Structural Equation Modelling: Concepts, Issues, and Applications. New York: SAGE. pp. 76-99.

Kelley, T.R., \& Knowles, J.G. (2016). A conceptual framework for integrated STEM education. International Journal of STEM Education, 3(1), 1-11.

Kruse, J., Edgerly, H., Easter, J., \& Wilcox, J. (2017). Myths about the nature of technology and engineering, The Science Teacher, 84(5), 39-43.

Lederman, N.G. (1992). Students' and teachers' conception of the nature of science: A review of the research. Journal of Research in Science Teaching, 29, 331-359.

Lederman, N.G., Abd-El-Khalick, F., Bell, R.L., \& Schwartz, R.S. (2002). Views of nature of science questionnaire: Toward valid and meaningful assessment of learners' conceptions of nature of science. Journal of Research in Science Teaching, 39(6), 497-520.

Liang, L.L., Chen, S., Chen, X., Kaya, O.N., Adams, A.D., Macklin, M., \& Ebenezer, J. (2008). Assessing preservice elementary teachers' views on the nature of scientific knowledge: A dual-response instrument. AsiaPacific Forum on Science Learning and Teaching, 9, 1-20.

Lincoln, Y.S., \& Guba, E.G. (1985). Naturalistic Inquiry. New York: SAGE.

McComas, W.F., \& Olson, J.K. (1998). The nature of science in international science education standards documents. In: McComas, W.F., (Ed.), The Nature of Science in Science Education: Rationales and Strategies. Netherlands: Kluwer Academic Publishers. pp. 41-52.

McComas, W.F., Clough, M.P., \& Almazroa, H. (1998). The role and character of the nature of science in science education. In: McComas, W.F., (Ed.), The Nature of Science in Science Education: Rationale and Strategies. Netherlands: Kluwer Academic Publishers. pp. 3-39.

National Academy of Engineering and National Research Council (NAE \& NRC). (2014). STEM Integration in K-12 Education: Status, Prospects, and an Agenda for Research. Washington, DC: National Academies Press.

National Research Council (NRC). (2011). Successful K-12 STEM 
Education: Identifying Effective Approaches in Science, Technology, Engineering, and Mathematics. Washington, DC: National Academies Press.

NGSS Lead States. (2013). Next Generation Science Standards: For States, by States. Washington, DC: National Academies Press.

Peters-Burton, E. (2014). Is there a "nature of STEM"? School Science and Mathematics, 114(3), 99-101.

Pleasants, J., \& Olson, J.K. (2019). What is engineering? Elaborating the nature of engineering for K-12 education. Science Education, 103, 145166.

Rinke, C.R., Gladston-Brown, W., Kinlaw, C.R., \& Cappiello, J. (2016). Characterizing STEM teacher education: Affordances and constraints of explicit STEM preparation for elementary teachers. School Science and Mathematics, 116(6), 300-309.

Roehrig, G.H., Moore, T.J., Wang, H.H., \& Park, M.S. (2012). Is adding the $\mathrm{E}$ enough? Investigating the impact of $\mathrm{K}-12$ engineering standards on the implementation of STEM integration. School Science and Mathematics, 112(1), 31-44.
Saumure, K. (2008). Convenience sample. In: Given, L.M., (Ed.), The Sage Encyclopaedia of Qualitative Research Methods. New York: SAGE. pp. 697-698.

Srikoom, W., Faikhamta, C., \& Hanuscin, D.L. (2018). Dimensions of effective STEM integrated teaching practice. K-12 STEM Education, $4(2), 313-330$.

Veal, W.R. (2004). Beliefs and knowledge in chemistry teacher development. International Journal of Science Education, 26(3), 329-351.

Yalvac, B., Tekkaya, C., Cakiroglu, J., \& Kahyaoglu, E. (2007). Turkish preservice science teachers' views on Science-technology-society issues. International Journal of Science Education, 29(3), 331-348.

Zembal-Sual, C., Starr, M., \& Krajcik, J. (1999). Constructing a framework for elementary science teaching using pedagogical content knowledge. In: Gess-Newsome, J., \& Lederman, N., (Eds.), Examining Pedagogical Content Knowledge. Netherlands: Kluwer Academic. pp. 273-256.

Zollman, A., \& Mason, E. (1992). The standard's beliefs instrument (SBI) Teachers' beliefs about the NCTM's standards. School Science and Mathematics, 92(7), 359-364. 